\title{
Integration of Syrian Refugees and Turkish Students by Non-Formal Education Activities
}

\author{
Ruyam Kuçuksuleymanoğlu \\ Department of Educational Sciences, Uludağ University, Turkey
}

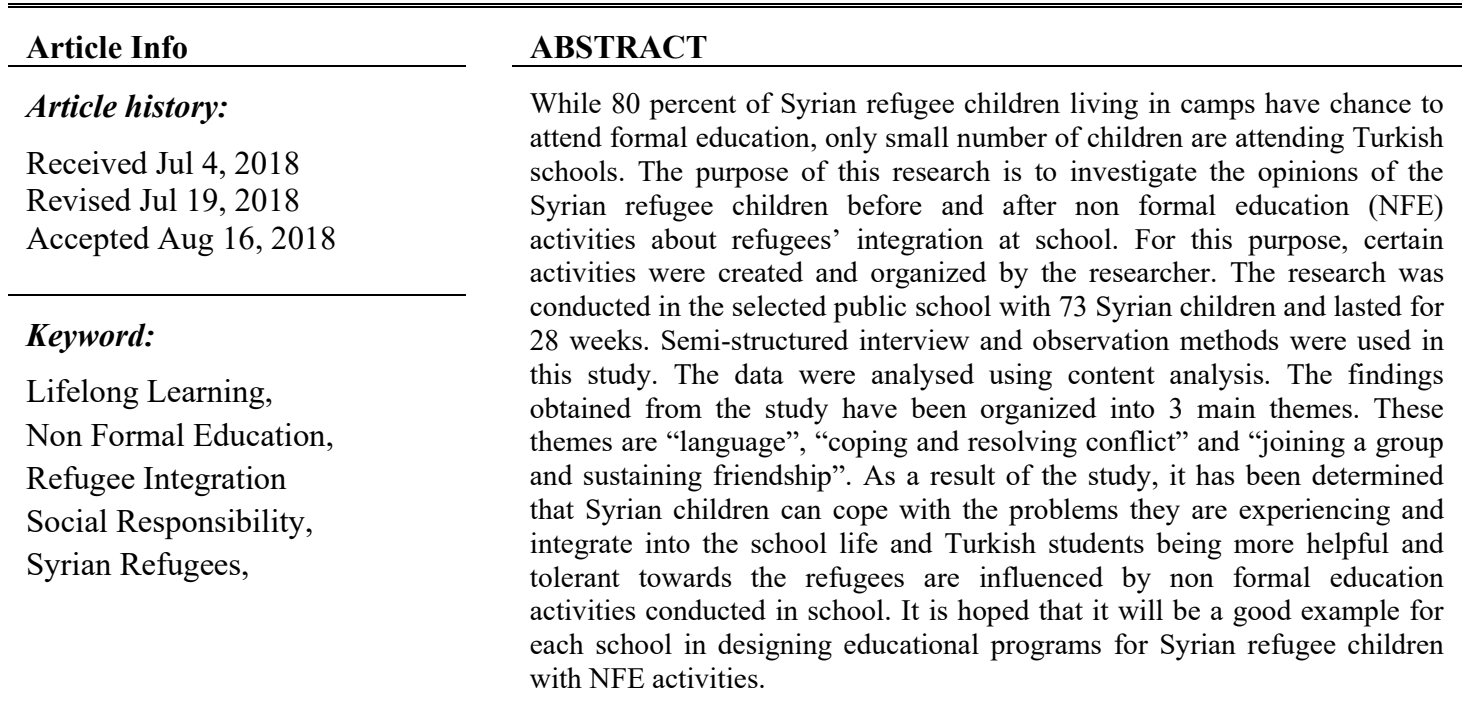

Copyright $\left({ }_{0} 2018\right.$ Institute of Advanced Engineering and Science. All rights reserved.

\author{
Corresponding Author: \\ Departement of Educational Sciences, \\ Uludağ University, \\ Gorukle Campus, Nilufer-Bursa, 16059, Turkey. \\ Email:ruyamk@uludag.edu.tr
}

\section{INTRODUCTION}

Arab Spring started in 2010 had given a start for many civil uprisings in the neighboring countries. United Nations declared that Syrian humanitarian crisis to be the worst faced so far in the 21st century [1] Due to the war in Syria, many people had to abandon their own homeland. 14 million Syrian citizens have taken refuge in neighboring countries and Syria has become one of the world's largest refugee countries. In the seventh year of Syrian civil war, the impact of the crisis on neighboring countries continues to deepen. According to statistics 43 percent of Syrians, displaced as refugees, live in Turkey [2]. To date, Turkey is home for 3,551,78 Syrian refugees, of which 1,490,033 are children; of which over 900,000 are estimated to be school-age children. Although UNICEF has introduced some Syrian children into the Temporary Education Centers (TEC) [3,1], about half a million of these children are enrolled in Turkish public schools which of most are at primary and secondary school level. Since June 2016, UNICEF has reported that more than 40 percent of school-age refugee children (380 thousand people) still can not go to school, despite a 50 percent increase in enrollment. With the law for Foreigners and International Protection entered into force by Turkey in 2014, all the refugees have the right to free access to health, education and labor market. Under this legislation, Turkey is obligated to provide free education for all school-age Syrian refugee children.

The contribution of immigrants to social communication in the countries where they go, is the most outstanding feature of education. Education enables immigrants to minimize the risks they may face within the host country. Increasing the influence of immigrants in the educational environment also increases the 
social cohesion of immigrants [4]. Therefore refugees' access to education has been the subject of academic and political enquiry Racism and bad emotions fed by immigrants can be solved through education [5]. Nearly all of the refugee studies emphasize that migrant children need education to adapt themselves to the new environment where they have migrated [6-11]. To learn the language of the new country is the crucial need for the refugees [12]. Learning the language of where they go allows them to take part in any situation in the country easily. [13, 14]. Besides learning a new language, the school environment also provides cultural interaction. The Syrians who came to Turkey as a refugee have already started to settle. In line with Turkey's policy, this means that these refugees will be permanent in Turkey in a very short time. From now on the Syrian children will live with the Turkish community and in the future they will be either the social capital or social problem of the country. To prevent from losing a generation of Syrian refugee children, formal and non formal education are possibly the first steps to help them to have a sense of full integration and live normally.

Non-formal education (NFE) is commonly known to be any organized, systematic, educational activity carried on, outside the framework of the formal system to provide selected types of learning to particular subgroups in the population; adults as well as children [15]. NFE is an organised educational process which takes place alongside the mainstream systems of education and training and does not typically lead to certification. NFE develops human capabilities, improves social cohesion and creates responsible citizens [16]. Flexible and diverse non-formal education plays an important role as a complement, an alternative, and a supplement to the formal education system. NFE enriches learning environments and promotes the learning of essential skills and competencies [17]. In non-formal education, most often what is learned is culturally valuable as it addresses the needs and interests of the learners. Consequently, non-formal education addresses specific learning needs and interests for the achievement of immediate personal outcomes [16]. These include education and training, knowledge and skills acquisition, enhancing the quality of life, reducing poverty and improving livelihood initiatives in regard to socio-economic needs. These outcomes assist participants in adapting to different situations, hence non-formal education is provided for adaptive responses [16]. The NFE also addresses the immediate-long-term structural consequences that require different people's attitudes. NFE is learner centred and practice based learning process with intrinsic motivation, which aims to provide identity growth, social change and integration into society with critical thinking abilities. As learning is voluntary, it is often linked to terms like 'experimental learning', 'empowerment', 'social pedagogy', 'participation', 'active citizenship' and 'social inclusion'. [17]. It is thought that in terms of adaptation of Syrian refugee children to their new life in Turkey, NFE is extremely important. NFE allows children to realize themselves in terms of cognitive and social development [18]. Through NFE, moral values can be taught, such as mediation, being respectful and tolerant of people [19]. Refugee children also acquire skills such as socio emotional development, and joining a group and sustaining friendship [20]. It makes it easier for them to learn the language of their asylum country, to visit their surroundings and to communicate with people [21]. Having been displaced from their countries, they need specialized programs that provide them with the necessary psychosocial, academic support. Therefore, the current study provides a precious understanding of how NFE activities have reached out to the Syrian refugee children. However, there is no study on how migrant children arriving in Turkey from Syria have benefited from NFE. This study will provide a different perspective into the school lives of Syrian refugee children living in Turkey and should inspire some other educators and school managers in designing educational programs for refugees. Although in recent years there has been an attempt to introduce students into nonformal education programs, the conceptions of Syrian refugee children about these education programs have not been systematically researched.

\subsection{Problem Statement}

As old as humanity, migration constitutes a process which affects the whole dynamics of social, cultural, political, and economic factors. Social interaction between communities living in harmony with the migration community seems to affect all society. In this process, educational activities that are carried out in educational institutions have an important role in terms of social cohesion. It has been observed that the Syrian refugee children have significant problems in orientating to social and school life in Turkey. The main problems are language, not accompanying with Turkish children, and prejudices, racist and violent attitudes against Syrian refugee children. The aim of this study is to investigate school environment improvements both in attitudes and behaviours of Syrian students due to NFE activities applied to them. For this purpose, answers to the following questions were sought.

1. What are the opinions of the Syrian refugee children about their school environment before the NFE activities?

2. What are the opinions of the Syrian refugee children about their school environment after the the NFE activities? 


\section{RESEARCH METHOD}

A social responsibility project was designed for the Syrian refugee children based on NFE activities. The main aim of this project was to create an environment where Syrian and Turkish students could learn from each other by using non-formal education activities, gain common habit of working together and accompany with each other, to help Syrian refugees' improve their Turkish speaking skills, break Syrian and Turkish children's prejudices against each other and minimize racist violence. For this purpose, certain activities were created and organized by the researcher. The main purpose of these activities are to minimize problems that exist between children, to help improve Turkish language skills and to learn how to be a team. All NFE activities were designed and applied under the headings shown below; Turkish Language Skills (Drama, Music, Fairytale Club); Racist \&Violent Attitudes (Drawings, Board Games, Outdoor Games); Working together (Talent Show, Night Tent Camp, Farewell Party).

Within the scope of this project, NFE activities have been organized, applied and directed for the Syrian refugees and Turkish children, by the researcher and a group of volunteering university students who has experience on NFE activities. For Turkish language skills 10 songs about cultural values were taught. Simple drama creations were used with emphasis on words and patterns that the Syrian could use in their daily and school lives. And fairy tales were read to emphasize common universal values. These activities were performed only for Syrian refugee children for the first 10 weeks, 12 hours per week. For the next 12 weeks, the similar activities were held for both Syrian and Turkish children.

For minimizing racist, violent attitudes and prejudices, activities in which Turkish and Syrian children were held together were organized. These activities were administered for 16 hours per week for 12 weeks. Among the activities the children drew pictures to the school walls, they played board games and some traditional Turkish outdoor games, they built sport teams (basketball, football, handball) and they revived "Survivor" (a very popular TV Show game focused on competition and solidarity).

To get in the habit of working together, and by this way in order to minimize the prejudices, all the children organized a talent show, they camped for a night in their school garden and in the last week they had farewell party where they danced, ate and enjoyed together.

This study was designed with the qualitative research methods. This study was phenomenological because it focused on understanding the lived experiences of students who shared a common experience. Narrative inquiry was the method implemented to gather and report the data from the participants. Clandinin and Connelly [22] defined narrative inquiry as "a way of understanding experience" by involving collaboration between the researcher and the participants, "over time, in a place or series of places, and in social interaction". This design was preferred since phenomenological approaches focus on how any individual or group experience is interpreted and how this meaning is conveyed [23].

\subsection{Sampling}

The research was conducted in the selected primary and secondary public schools. Participants in this qualitative research were 73 Syrian children in Bursa, Turkey. Of the 73 Syrian children, 36 were males and 37 were females. The interviews were conducted with 22 Syrian people (13 males-9 females). Among Syrian children, none could speak Turkish when they first came to Turkey. When the project was started, many of the Syrian children were at the beginner (A1, A2) level. The selection criteria were that all the Syrian and Turkish students were addressed by their school teachers. Teachers provided participation of all Syrian students in the activities, while academically less successful and a bit naughty Turkish students were chosen by school administrator and teachers participated in the project. The study lasted for an academic year (28 weeks).

\subsection{Data Collection}

Semi-structured interview and observation methods have been utilized in this study. In order to establish construct validity of the interview questions, the questions were sent to two academicians who worked with the Syrians to get their opinions. Based on their feedback, the interview form was organized. Because all students were students of the researcher, her observations and experiences with them were also considered. During the data collection, the interviews were recorded and short notes were taken by the researcher. Triangulations of sources and of methods were accomplished to ensure their validity and reliability [23]. Semi-structured interviews, documents, field observations were compared and contrasted. Finally, an outside researcher was asked to analyse the same data separately. The interviews were conducted with the children by the researchers between November 15th, 2016 and May 20th, 2017. Since the Syrian children did not know sufficient Turkish, through the help of 3 Arabic interpreters who are university students from Syrian backgrounds, the researcher was able to interview. The interviews with the participants were recorded by mobile phone and then transcribed before analysis. Guaranteeing confidentiality, anonmity and the right to the withdraw from the study at any point were translated into Arabic to ensure that

IJERE Vol. 7, No. 3, September 2018: $244-252$ 
participants fully understand the research. Each interview took nearly an hour. In order to hide the identity information of the children whose views were heard in the research, only the names of the children were used. To ensure the reliability of the interviews, the interviews were conducted in a setting where there were only the researcher, children, and the interpreters. The researcher had the privilege of observing all the children for 28 weeks first hand, as their teacher, and interacted with all these students throughout the project.

In qualitative research, the concept of "trustworthiness" is considered instead of validity and reliability. Various credibility criteria have been taken into account in the process of this research. In the analysis phase of the data, a comprehensive view point was sought to be drawn up in the creation of the code list and in the interpretation of the findings by searching the relevant literature. All records in the data collection and analysis process are kept regularly. All data sources are cited.Methodological triangulation has been provided through interviews, observations and document examinations in the research. Patton (2002) stated that using more than one method would make the research more qualitative.

\subsection{Data analysis}

Content analysis which is one of the significant techniques with frequent use seeking to present the problem in a systematic way, was used to analyse the data. In analysis, the raw data were first identified, and then common points were found in the responses given and then codes were created. The categories and themes of the data were identified through an open coding process in which the interviews, field notes and observations were analysed through line-by-line coding and analysis. First, data is listened and read many times to decide coding process. Then, data were coded. Later those codes were collected under some themes. Themes were identified through the codes, and then sub themes composing the themes were identified.

\section{RESULTS AND ANALYSIS}

Children continue to be the ones that pay the biggest price in the face of the crisis and carry the heaviest burden. Due to the results of the interviews and observations the findings obtained from the study related to school environment changes and improvements both in attitudes and behaviours have been organized into 3 main themes. These themes are "language", "coping and resolving conflict" and "joining a group and sustaining friendship".

Syrian children have stressed out that they are experiencing various problems both in social and school life because of language. The most important point, that since Syrian children don't speak Turkish fluently, they can not communicate with neither their teachers nor peers easily. This situation necessitated the reception of help from Turkish students at the point of communication with people. In cases where they could not get help, language misunderstandings caused some other misunderstandings. For this reason, they don't socialize and are left out of the groups either on the playground or especially in the classroom. They feel themselves alone and isolated. Further more, they are not successful academically. Syrian students are having difficulty attending the classes and being successful in the academic sense because the teachers can not help the students sufficiently. Most of the Syrian students learn Turkish to express themselves but very little of them learn reading and writing precisely and neatly. After the studies, Syrian children who learned Turkish have stated that they feel better at school and on playing grounds. They also stated that they can make friends more easily, understand what is taught in the lessons and be successful academically. (Table 1)

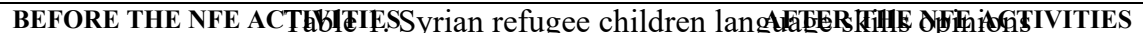

"Learning Turkish is very difficult. People don't understand me "Now I can speak Turkish quite well than any other
when I speak Turkish and some of them mock me" (Raha/Madel)

"I can't tell my feelings and desires because I don't speak enough Turkish. I don't understand the conversations in the

"I've started learning Turkish. Now I can tell what I want and classroom or in the playground" (Nour)

"I can barely speak Turkish. I'm having fun while playing in the playground but I get bored during the lessons" (Velid)

"I could not communicate in Turkish when we came to Turkey, so I felt very alone and in fact I am still alone" (Saad) the others play with me" (Raha)

I don't get embarrassed while talking Turkish. I don't get upset like I used to do when people laugh at me. I laugh at myself, too.(Fateh)

"I feel free while talking Turkish. I also don't fear that people are going to beat me up" (Saad) 


\section{BEFORE THE NFE ACTIVITIES}

"I have poor grades because I can't speak Turkish. The teacher never shows interest in me in classes, she never asks me questions. Because I can 't understand the questions in the exam I can't answer any of them" (Najmad/Betul)

"I don't study from my Turkish books because I don't know how to read. It is very difficult here without friends and without the ability to communicate in Turkish" (Mohamad)

"I was scared at first because I did not understand Turkish" (Fateh)

"I have nothing and understand nothing. I feel both embarrassed and scared" (Samer)

"The teacher never shows interest in me in classes, she never asks me questions. Because I can't understand the questions in the exam I can't answer any of them" (Abdulhakim)

\section{AFTER THE NFE ACTIVITIES}

"I've started learning Turkish. Now I can tell what I want. I don't get upset like I used to do when people laugh at me." (Najmad)

"I can speak Turkish well, I understand what people say but still can't read. Reading is very difficult" (Betul)

"I hate lessons because I still have difficulty understanding what the teacher says, I can not read the books. But I am very comfortable with my friends while playing and sharing" (Abdulhakim)

"I understand and respond to what teachers say in class now" (Mohamad)

"When we learned Turkish, we started to get better" (Velid)

“We learned Turkish and they learned a little Arabic” (Madel)

'Now we are starting to speak Turkish. Some even can swear" (Taha)

"We started to understand each other. A little Turkish, a little Arabic. There was a mixed language" (Zakaria)

With the migration, the living space of the individual changes and new associations emerge, cultural cohesion or conflict and social problems can be experienced. Syrian refugee children participating in this study suffered culture shock as they moved to Turkey. Syrian children have begun to evaluate cultural differences, not cultural affinities, during their actual refugee experiences. They struggled with adapting to a culture foreign to them and trying to understand and establish a new life. During their first few weeks in Bursa, Turkey, they all felt overwhelmed, and most expressed a desire to return to Syria. The most striking reason for that is Syrian children feel themselves excluded. Obtained from interviews, it is seen that the idea of having similarities between the cultural meaning of the information in Syria and Turkey have lost its supportability for the Syrians with negative experiences in social terms. Moreover, they are angry because of the feelings of being alone and helpless. They have conflict with the other children. But after the NFE activities Syrian children started to cope with the Turkish. (Table 2)

Table 2. Syrian refugee children coping \& resolving conflict opinions

\footnotetext{
BEFORE THE NFE ACTIVITIES

"The beginning was very difficult. I felt lost. I used to cry at nights. I hated everybody and everybody hated me" (Zakaria)

"We fight with Turkish boys. Sometimes they win sometimes we win" (Abdulkader)

"When I immigrated to Turkey I dreamed to have a peaceful and good life and better future, the same as the dream of all Aleppo immigrants but all I found was a gap. Here we have another war. The war to struggle and survive" (Dibo)
}

"I miss my home. I dream about my friends and my school every night. I want to go back home after the war is over. I couldn't get used to here and don't know if I want to" (Madel)

AFTER THE NFE ACTIVITIES

"We do not fight as much as the old days" (Nour)

"I locked a Turkish girl to the bathroom once. Now I'm very sorry for what I did" (Fateh)

"I think we're getting used to each other now. We do not fight like we used to be. After all, we are friends" (Betul)

"I don't fear anymore that people are going to beat me up. I have very good Turkish friends" (Madel) 


\author{
BEFORE THE NFE ACTIVITIES \\ "I am afraid to go out on the street alone. I never want to be alone \\ in school. I realized how difficult it would be for me" (Velid)
}

"These months have been a little confusing because of the changes. I start from zero"(Fateh)

"I am so afraid of being beated. I am never alone at school. I am afraid even when I go to the bathroom" (Taha)

"I'm scared of walking around alone now" (Fatma)

"I feel depraved, depressed and mobbed" (Ahmad/Samer)

\section{AFTER THE NFE ACTIVITIES}

"I don't cry a lot anymore. This is my new home. I will get used to it despite the difficulties" (Ahmad)
"They do not call me Arab anymore. They learned that I am Syrian" (Abdulkader)

"I don' want to die anymore. The life ahead of me will be beautiful. I want to believe that. I'm peaceful, from now on this is my school. We are not going to go back to Syria" (Saad) "I will live here. I really love my teacher and the "big sisters and brothers". They are really nice

people and they treat me very politely" (Zakaria)

"I have Turkish friends who love me. I am not scared anymore for being beated and hit" (Dibo/Fatma)

"My life is now here. When we first arrived, I wanted to return because I didn't like here and "felt lost" without anything. Now I solved my problems." (Velid)

All participants expressed their feelings of sadness, frustration, and despair as they first enrolled in school. At the beginning of the study, some of the Syrian students had prejudices against the Turkish. Some of them confessed that they bullied the Turkish children many times verbally or physically. Some students were raging against the thrills. Some did not know why they hated Turkish children. They stated that they did not have any friends at the beginning but later they started to establish new friendships, join different groups and start to enjoy their lives at school with NFE activities. Since Syrian and Turkish children did not know each other and did not understand each other's languages, they were having difficulty making friends at the beginning of the project. After NFE activities they have become familiar with each other, they could become friends easily. They joined each other's groups and learned how to work and play together. (Table 3)

Table 3. Syrian refugee children join group\& sustain friendship opinions

\begin{tabular}{|c|c|}
\hline BEFORE THE NFE ACTIV & FTER THE NFE ACTIVITIES \\
\hline $\begin{array}{l}\text { "I have Syrian friends and we play together. We play Syrian } \\
\text { games" (Nour) }\end{array}$ & $\begin{array}{l}\text { "I feel connected to this special place I love my school } \\
\text { and friends" (Mohamad) }\end{array}$ \\
\hline $\begin{array}{l}\text { "I am really sad about leaving my friends and other family } \\
\text { members, especially my grandparents" (Samer) }\end{array}$ & $\begin{array}{l}\text { "We have a lot of fun when we play the same games" } \\
\text { (Nour) }\end{array}$ \\
\hline $\begin{array}{l}\text { "When we came to Turkey, I felt "very alone." Still I am alone" } \\
\text { (Duha) }\end{array}$ & $\begin{array}{l}\text { "Some friends are teaching me. They teach me Turkish; I also } \\
\text { teach them Mathematics" (Duha) }\end{array}$ \\
\hline "I do not feel like belonging to any group. But there & friends?" (Taha) \\
\hline people around me in Syria" (Fatma) & couple of months, \\
\hline "Sometimes I sit alone all day" (Abdul el Nasır) & turn" ( \\
\hline $\begin{array}{l}\text { "How can I be friends with them? They neither understand what } \\
\text { we say, nor play the same games as we do. They are very strange" }\end{array}$ & $\begin{array}{l}\text { "I am more hopeful about my future. I'm starting to see this place } \\
\text { as a home now" (Fatma) }\end{array}$ \\
\hline (Raha) & chool was "too hard". I did not know anyone, \\
\hline & "I like to do the same activities with Turks" (Abdulkader) \\
\hline & $\begin{array}{l}\text { "Do you know they look very much like us? I am very } \\
\text { surprised that we have a lot of similarities" (Amani) }\end{array}$ \\
\hline
\end{tabular}

\section{DISCUSSION}

Not only Syrian refugee children but also academically less successful and somehow naughty or academically less successful Turkish children are disadvantaged vulnerable groups as they have many barriers to integrate into socio cultural life at schools. As a result of the study, it has been determined that Syrian children can cope with the problems they are experiencing and integrate into the society they live in 
and Turkish students can be more helpful and tolerant towards the refugees by non formal education activities conducted in school.

There are not any quick leaded Turkish language courses in the schools to provide support for the refugee children, therefore it makes it difficult for them to enroll and achieve academic success in the school system. Turkish language knowledge for refugees is a major obstacle to obtain social cohesion. It is considered that the Ministry of National Education is carrying out some deficient policies on teaching Turkish to refugee children. Especially in the early years of immigration, education in the camps was given in Arabic and there was not much interest in teaching Turkish as it was thought that the refugees would return to their countries. Later, it was observed that those who had left the camps and migrated to the cities experienced difficulties related to the language. As [24] argues the host language is a critical capability for migrants, which enables them to access goods, services and the labour market in the host country. Learning to communicate orally in Turkish requires time; it is quite difficult for the Syrian refugee children to master Turkish culturally and linguistically (especially writing and reading) only with school courses. With NFE activities, the children learned Turkish language easily and more quickly. The feelings of despair, isolation, and loneliness of Syrian refugee children were replaced by the successes they experienced once they learned Turkish and cope with the others in academic and social life. Communicating in the same language strengthened the ties between Turkish and Syrian students and brought all the children together. This findings support [11] Rutter's results which highlighted the critical role of host language as a tool for inclusion and integration host society'language.

It has been determined that racist discrimination and conflict is another huge problem. Syrian children play with other Syrian children and Turkish children and play with other Turks. The findings are similar to the results of $[10,25]$ who assigned that refugees increasingly face exclusion an $\mathrm{d}$ discrimination The reason behind discrimination and conflict can be explained by similarity-attraction paradigm [26], which argues that people are affected by those similar to them. Accordingly, individuals do not like the individuals who are in the environments that are not similar to their own culture, and they have difficulty in establishing communication. The studies conducted in the scope of the race/ethnicity also show that people want to be together with the people sharing the same race or ethnical roots [27]. On all these grounds, the conflict between the Syrian and the Turkish children causes problems and sometimes gang fights. Besides, Syrian children who do not adapt to their new country Turkey, tend to commit crimes. From time to time, there are debates going on to swear and fight among children. As [1] argues, Syrian children risk being 'a lost generation' whose dreams and opportunities for the future in their own country of birth have been eroded by the civil war. With NFE activities both the Syrian and Turkish children start to learn to coorperation. They are motivated to act toward a shared desired goal. Social identity creates strong social interactions between the individuals within the same group, and leads to development of dependency among the members [28] due to that, Syrian refugee children and Turkish children should manage to work together in cohesion.

The friendship and close relationship that Syrian children would establish with Turkish children would help them to learn about their new county and its culture and to acquire behaviours compatible with this culture. All the children that have taken part in the activities learned to be more tolerant and understand each other. They now understand that there may be differences between people and nations, but they can resolve these differences by compromising rather than fighting. According to [29]'s research; individuals with high social skills could be more successful in self-directed learning behavior such as implementing own study plans, searching for support when learning problems are encountered, good time management, determining own learning targets, and having high expectations for learning performance. Having such skills with NFE will make Syrian refugee children an important human human asset for them and the country in the future.

After being friends, Syrian children joined different groups at school and felt themselves more comfortable and peaceful. Playing together, struggling for the same target, communicating with each other led Syrian refugee children to looking forward to the future with hope. Education has been much debated in the literature, with the dominant approaches being identified as the human capital approach; the human rights approach; and the social justice approach [33, 32]. Within the human capital approach, for example, education quality is viewed as contributing to economic development focusing on economic gains [34,35] in terms of 'supporting livelihoods, generating income and reducing human insecurity' [32].With the light of all those eeaving Syrian refugee children totally in their own culture under the notion of education might lead to unwanted results for both Turkey and Syrian migrants. [28, 30].

\section{CONCLUSION AND IMPLICATIONS}

As the population of immigrant Syrian students continues to grow at a rapid rate, it brings both wealth and difficulty to the schools. On one hand cultural diversity is wealth but on the other hand it is a 
giant problem. To change the negative effects of the refugees to the positive, schools, NGOs and volunteers can manage NFE activities for the students. It is thought that improving NFE programs for Syrian refugee children in Turkey and providing a sustainable solution that enhance the integration of the refugee children rather than temporary solutions is precious. For this reason, non-formal education studies related to Syrian migrations in Turkey should be emphasized especially by the academia because academic knowledge about refugees will facilitate the process.

It is imperative that Syrian refugee children must go to school as the social capitals of the future and must adapt to their new country primarily at schools. Now only about 10 percent of the Syrians in Turkey are housed in camps. The others are being scattered in the cities and are still living without control. In conducting NFE activities for the refugees, school administrators who have Syrian students can benefit from universities and NGOs. Ministry of National Education should immediately prepare a holistic and inclusive plan about setting policies for the integration and education of refugee children. However, the findings obtained might provide ideas and constitute an example for the future studies. Yet, more, different and associated research is required with regard to adaptation of Syrian refugee children. It is of primary importance to increase access to quality education opportunities at all levels through organized, formal and non-formal education in order to ensure that all Syrian children in school are educated. It is imperative that Syrian children benefit from both inclusive and participatory learning opportunities to support their own personal development and to promote positive norms and behaviours. Providing an environment in which universities and volunteers can take an active role in is very important for some matters such as learning opportunities and social events. Syrian children's education and protection needs in Turkey are very large and constantly increasing. To overcome these difficulties, the Government of Turkey is trying to prevent Syrian children to become a 'lost generation'. To strengthen the quality of education and to have more inclusive systems, education authorities should benefit from NFE activities

\section{REFERENCES}

[1]. UNICEF, (2017). "Preventing a Lost Generation in Turkey". [Online] Available: http://www.unicef.org.tr /files/bilgimerkezi/doc/UNICEF\%20TCO_Fact\%20Sheet_01.2017.pd f

[2]. Turkiye Ucuncu Sektor Vakfi (TUSEV) (2015). Uye Etkinligi Suriyeli Multecilerin Durumu (The Status of the Syrian Refugees). Retrieved on April 1, 2016 from: http://www.tusev.org.tr/usrfiles/files/Suriyeli_Multecilerin_Durumu_Toplanti_Notlari_pdf

[3]. Human Rights Watch. (2015). "When I picture my future, I see nothing". [Online] Available:https://www.hrw.org/report/2015/11/08/ when-i-picture-my-future-i-see-nothing/barriers-

[4]. Tubergen, F. V., \& Werfhorst, H.V. (2007). "Postimmigration Investments in Education: A Study of Immigrants

[5]. Finch, B.K., Kolody, B., \& Vega, A.W. (2000). "Perceived discrimination and depression among Mexicanorigin

[6]. Adam, L. D, \& A. Kirova. (2006). Global Migration and Education: Schools, Children and Families. Mahwah, NJ: Lawrence Erlbaum Associates, Routledge

[7]. Bourgonje, P. (2010). "Education for Refugee and Asylum Seeking Children in OECD Countries." Education International 50: 1-12.

[8]. Madziva, R., Thondhlana, J. (2017) Provision of quality education in the context of Syrian refugee children in the UK: opportunities and challenges Compare 47 (6) 942-961

[9]. Osadan, R., and E. Reid. (2016). "Recent Migrants and Education in the European Union." Compare: A Journal of Comparative and International Education 46 (4): 666-669.

[10]. Reynolds, G. (2008). The Impacts and Experiences of Migrant Children in UK Secondary Schools. Research Working Paper No, 47. Sussex: Sussex Centre for Migration.

[11]. Rutter, J. (2006). Refugee Children in the UK. Maidenhead: Open University Press

[12]. Toppelberg, C.O., \& Collins, B.A. (2010). "Language, culture, and adaptation in immigrant children". Child and Adolescent Psychiatric Clinics, 19 (4), 697-717. DOI: http://dx.doi.org/10.1016/j.chc.2010.07.003

[13]. Kulick, D., \& Schieffelin, B. B. (2004). "Language socialization”. In A. Duranti (Ed.), The handbook of linguistic anthropology (pp. 349-368). Oxford: Blackwell Publishing.

[14]. Watson-Gegeo, K. A. (2004). "Mind, language, and epistemology: Toward a language socialization paradigm for SLA". The Modern Language Journal, 88(3), 331-350. http://dx.doi.org/10.1111/j.0026-7902.2004.00233.x

[15]. Sevdalis, C. and Skoumios, M. (2014) Non-formal and Informal Science Learning: Teachers' Conceptions The International Journal of Science and Society, 5, 13-25.

[16]. UNESCO, (2014).Evaluation of Let Us Learn Nepal: After-School Programme for Girls and Girls Access to Education Programme [Online]Available:https:/www.unicef.org/evaldatabase/index_81851.html

[17]. Festeu, D \& Humberstone, B. (2006). Non-formal Education through Outdoor Activities Guide. European Institute for Outdoor Adventure Education and Experiential Learning [Online] Available: https://scholar.google.com.tr/scholar?q=Festeu+and+Humberstone\&btnG $=\& h l=\operatorname{tr} \&$ as $\quad \mathrm{sdt}=0 \% 2 \mathrm{C} 5 \quad$ adults in California". Journal of Health and Social Behavior, 41(3), 295-313.

[18]. Geidne, S., Fredriksson, I. \& Eriksson, C. (2016). "What motives are important for participation in leisure-time activities at Swedish youth centres?" Health Education Journal, 75(8), 972-985.

[19]. Opic S, Duranovic M (2014). Leisure time of young due to some socio-demographic characteristic. Social and Behavioral Science (159): 546-551. 
[20]. Stodolska, M. (2000). "Looking beyond the invisible: Can research on leisure of ethnic and racial minorities contribute to leisure theory?" Journal of Leisure Research, 32(1), 156-160.

[21]. Heo, J ., \& Lee, Y. (2007). "I don't want to feel like a stranger: Korean students who play basketball seriously". Leisure, 31(1), 133-154.

[22]. Connelly, F. M., \& Clandinin, D. J. (2000). Narrative understandings of teacher knowledge. Journal of curriculum and supervision, 15(4), 315-331.

[23]. Patton, M.Q. (2014). "Qualitative Research \& Evaluation Methods". Thousand Oaks, CA: SAGE Publications.

[24]. Tikly, L. (2016). "Language-in-Education Policy in Low-Income, Postcolonial Contexts: Towards a Social Justice Approach." Comparative Education 52 (3): 408-425

[25]. Tereshchenko, A., \& L. Archer. (2014). New Migration New Challenges: Eastern European Migrant Pupils in English Schools. https://www.naldic.org.uk/Resources/NALDIC/Research\%20and\%20 Information/documents/Tereshchenko\%20\%20Archer\%20-East Euro Pupils Report .pdf.

[26]. Osbeck, L.M., Moghaddam, F.M., Perreault, S., (1997) Similarity and attraction among majority and minority groups in a multicultural context. International Journal of Intercultural Relations 21(1):113-123

[27]. Martins, L. L., Milliken, F. J., Wiesenfeld, B. M., \& Salgado, S. R. (2003). Racioethnic diversity and group members' experiences: The role of the racioethnic diversity of the organizational context. Group \& Organization Management, 28(1), 75-106.

[28]. Mannix, E.; Neale, M.A. (2005) What differences make a difference? The promise and reality of diverse teams in organizations.Psychological Science in the Public Interest. 6 (2), 31-55.

[29]. Engin, M. (2017). Analysis of Students' Online Learning Readiness Based on Their Emotional Intelligence Level. Universal Journal of Educational Research 5(12A): 32-40. DOI:10.13189/ujer.2017.051306.

[30]. Tirone, S., \& Goodberry, A. (2011). "Leisure, biculturalism, and second-generation Canadians". Journal of Leisure Research, 43, 427-444.

[31]. Kim, J., Heo, J., \& Kim, J. (2014). "The benefits of in-group contract physical activity involvement for health and well-being among Korean immigrants”. International Journal of Qualitative Studies On Health and Well-Being, 9(1), 1-11.

[32]. Tikly, L. (2011). "Towards a Framework for Researching the Quality of Education in Low-Income Countries." Comparative Education 47 (1): 1-23.

[33]. Tikly, L., \& A. M. Barrett. (2011). "Social Justice, Capabilities and the Quality of Education in Low Income Countries." International Journal of Educational Development 31 (1): 3-14.

[34]. Hanushek, E. A., \& J. A. Luque. (2003). "Efficiency and Equity in Schools around the World." Economics of Education Review 22 (5): 481-502.

[35]. Heyneman, S. P. (2004). "International Education Quality". Economics of Education Review 23 (4): 441-452.

\section{BIOGRAPHY OF AUTHOR}

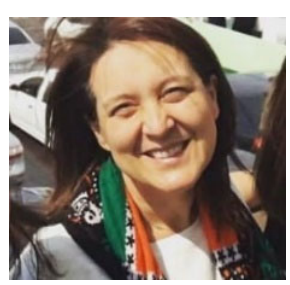

Ruyam Kuçuksuleymanoğlu is associated proffesor in Educational Planning and Administration Department at Uludag University, Bursa, Turkey. She completed her Masters and PH. D. degrees on educational sciences. She conductds national and international projects especially on social responsibility and social entrepreneurship. She is interested in classroom management, strategic planning, international students and organizational image. 